\title{
中国大陆地区 $L_{g}$ 波速度、衰减和震级*
}

\author{
葛涣称倪岳伟 黄才中 \\ 李敬华 李永勤 蒋耀明 鹿芬震 \\ （江苏省地震局，南京）
}

\section{关键词 $L z$ 辰级、衰减}

广泛搜集了分布于中国大陆(除新疆、西藏外)地区的 250 个区域台站、200多个地的短 周期记录资料, 分五个区(东北、西北、东部、西南和华南)测定了 $L_{z}$ 波的群速度、水平向与竖 直向振幅比 $H / Z$ ( $H$ 取 EW 和 NS 向振幅的算术平均值)、衰减系数 $r$ 值, 并确定了中国大陆 地区统一 $m_{L}$ 。震级标度 (图 1).

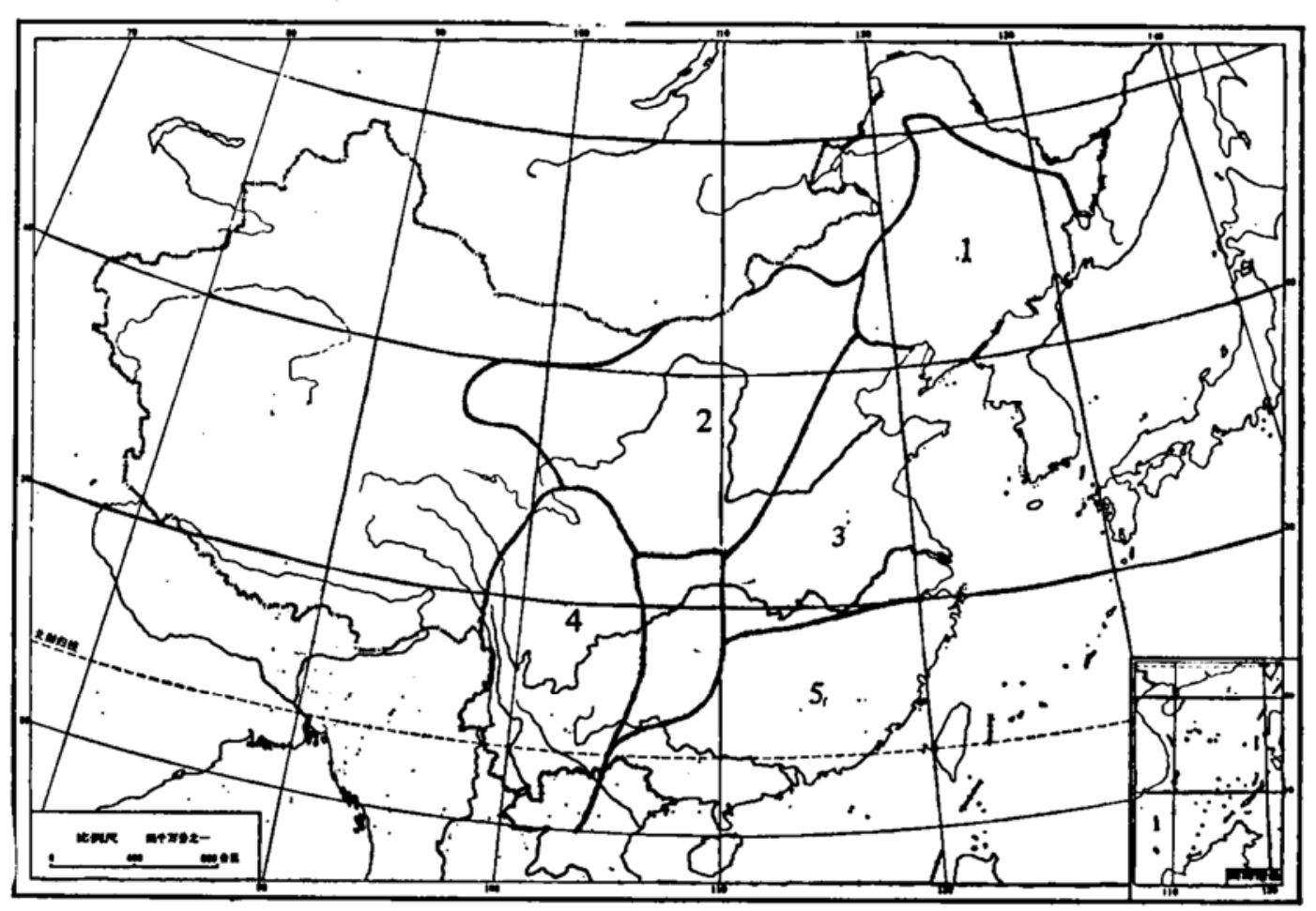

图 1 中国五大区 $L_{\mathrm{g}}$ 波的群速度、 $r$ 和 $Q$ 值分布图
1.东北 $\frac{3.52}{2.7 \pm 0.4} \mid \frac{}{550 \pm 81}$;
2. 西北
$\frac{3.56}{2.1 \pm 0.2} \mid \frac{3.34}{599 \pm 56} ;$
3. 东部 $\frac{3.54}{3.4 \pm 0.1} \mid \frac{3.27}{103 \pm 12}$;
4.西南 $\frac{3.52}{3.1 \pm 0.4} \mid \frac{3.24}{445 \pm 57} ;$
5. 华南 $\frac{3.54}{2.2 \pm 0.1} \mid \frac{3.33}{562 \pm 26}$.
图例 $\frac{V_{18}(\mathrm{~km} / \mathrm{s})}{r\left(\times 10^{-3} \mathrm{~km}^{-1}\right)} \mid \frac{V_{\max }(\mathrm{km} / \mathrm{s})}{Q}$

·本文 1989 年 2 月 23 日收到.

- 本文系地篗科学联合基金资助课题. 


\section{一、 $\boldsymbol{L}_{\mathrm{B}}$ 波的群速度}

$\boldsymbol{L}_{\mathbf{a}}$ 波可解释为大陆地壳内传播的高阶振型面波 ${ }^{[1]}$, 或解释为地壳内多次全反射 $S$ 波组成 的导波 ${ }^{[3 .}$. 在数千公里内, 大陆地很的短周期记录上 $L_{z}$ 波是最显明的波群. 不少分析人员 常将 $L_{8}$ 波误认为直达波 $\bar{S}^{[3]}$. 图 2 示出一张典型的 $L_{8}$ 波近霞记录地震图.

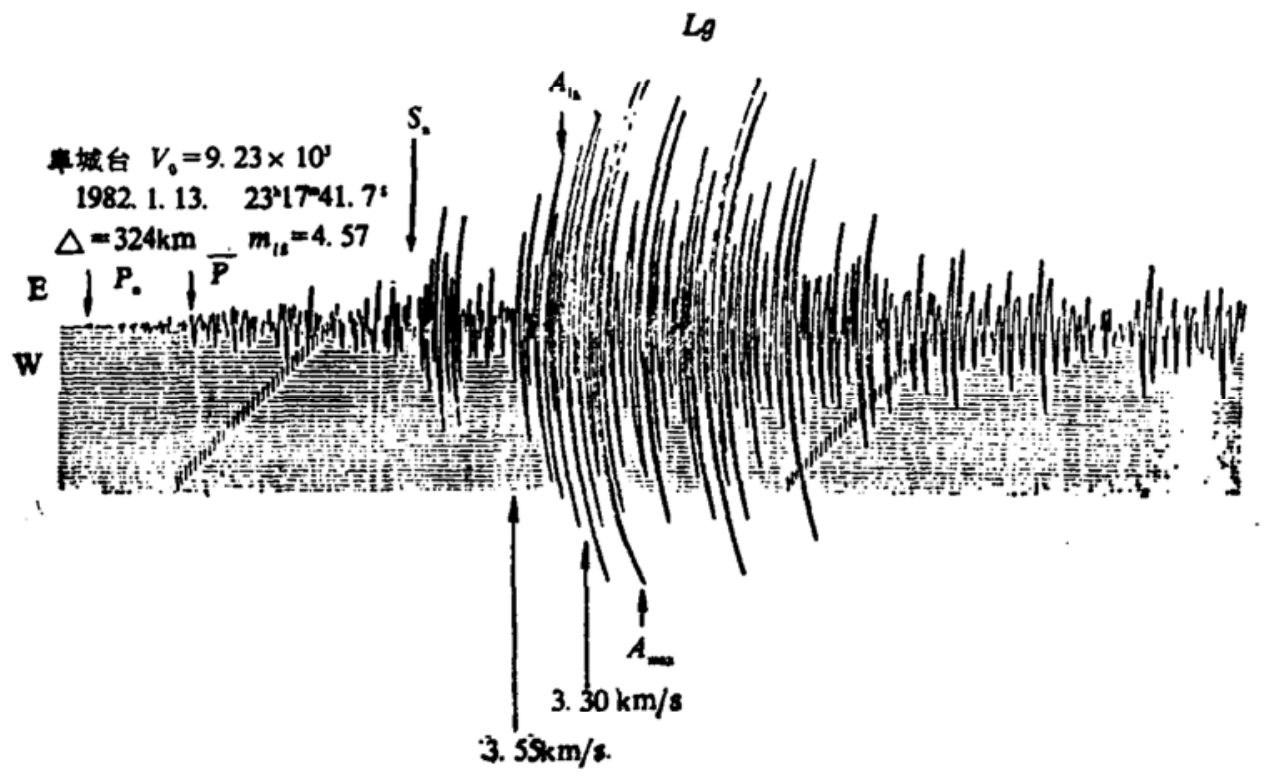

图 $2 L_{\mathrm{z}}$ 波典型地震图

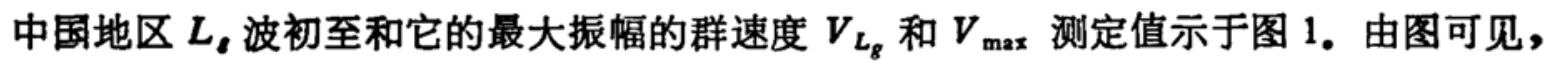
中国地区的 $V_{L_{z}}$ 在 $3.52-3.56 \mathrm{~km} / \mathrm{s}$ 之间, 平均为 $3.54 \pm 0.02 \mathrm{~km} / \mathrm{s}$. 该值与全球大陆约 3.5 $\mathrm{km} / \mathrm{s}$ 左右的 $V_{L_{\mathrm{g}}}$ 值一致. 此外, 中国大陆的 $V_{\max }$ 值在 $3.24-3.34 \mathrm{~km} / \mathrm{s}$ 之间(缺东北区数 据), 平均为 $3.30 \pm 0.05 \mathrm{~km} / \mathrm{s}$.

\section{二、 $L_{8}$ 波的 $H / Z$ 值}

中国各区 $L_{z}$ 波的 $\log (H / Z)$ 值观测结果表明: $\log (H / Z)$ 值与台基性质之间是相关 的. 在坚硬的花岗岩类台基上, $\log (H / Z)$ 值很小,平均为 0.05 ; 而在松散沉积台基, 平均高 达 0.50 ; 对于沉积岩类台基, $\log (H / Z)$ 居中,平均为 0.11 .

\section{三、 $\gamma$ 和 $\boldsymbol{Q}$ 值}

$L_{z}$ 振幅 $A$ 随震中距 $\Delta$ 的衰减道循如下规律 ${ }^{[4]}$ :

$$
A-A_{0} \Delta^{-5 / 6} \exp (-r \Delta),
$$

这里 $A_{0}$ 为源振幅, $\Delta^{-5 \%}$ 为几何衰减项, $r$ 为 $L_{8}$ 波的衰减系数.

分别 $\mathrm{Z}$ 和 $H$ 向测童 $L_{z}$ 波的最大持续振幅 $A_{L g}$ （定义为 3.55 至 $3.30 \mathrm{~km} / \mathrm{s}$ 之间的第三大 振幅)和 $L_{z}$ 波群的最大振幅 $A_{\max }$, 得到四种振幅 $A_{L s s} 、 A_{L s h} 、 A_{\mathrm{mxz}}$ 和 $A_{\mathrm{mxh}}$, 合计 5049 个 振幅数据, 平均周期 0.7s. 利用葛焕称等 ${ }^{[3]}$ 的综合回归计算法, 分别计算四种振幅的 $r$ 值. 各 振幅的 $\gamma$ 值差均在误差范围内, 故取其平均作为 $L_{z}$ 波 $\gamma$ 值. 最后得到中国五大区 $L_{s}$ 波 $r$ 
值, 见图 1. 全国平均 $r$ 值为 $0.0027 \pm 0.0006 \mathrm{~km}^{-1}$. 同时根据关系: 品质因子 $Q-\pi / r U T$ ( $U$ 为群速度, $T$ 为周期), 分别对 $A_{L}$ 和 $A_{\text {max }}$ 计算 $Q$ 值, 取其平均, 作为各区的 $L_{d}$ 波 $Q$ 值, 约 在 400 至 600 之间,亦示于图1. 全国平均 $Q$ 值为 500 .

各分区的 $L_{z}$ 波 $r$ (或 $Q$ )值的分布图表明: $r$ (或 $Q$ ) 值与新化代沉积层的厚度和区域构 造特征存在着关系. 东部和西南为相对高 $\gamma$ 值区; 西北和华南为相对低 $\gamma$ 值区; 东北区的 $\gamma$ 值 恰为全国平均值. 东部和西南, 西北和华南的 $r$ 值均近似相等, 其差在误差范围内. 高 $r$ 值的 东部区给处于低洼的华北大平原和长江中下游平原的整个范围内, 具有很 厘 (平均 2500$4500 \mathrm{~m}$ ) 的新生代沉积. 西南区的沉积层虽然少而薄, 但其境内密布一系列规模巨大、活动明显 的深大断裂, 新构造运动强烈, 这可能导致 $L_{\varepsilon}$ 波的高衰减. 低 $r$ 值的西北和华南区均为稳定 的地块. 西北区虽然新生代沉积分布较广, 但厚度仅平均约 60-100 m. 华南区境内岩浆岩广 为分布, 新生代沉积仅有零星分布. 东北区在中部平原有较厚 (平均 $1600-6000 \mathrm{~m}$ ) 的新生代 沉积, 而在东、西和北部为山岭, 岩浆岩出露, 故此形成了居中的 $r$ 值.

\section{四、中国大陆 $m_{L_{g}}$ 震级标度}

Herrmann 和 $\mathrm{Kijko}^{(6)}$ 推荐的 $L_{8}$ 震级标准化公式可改写成如下形式:

$$
m_{L_{g}}(f)=\log A_{L_{g^{z}}}+\frac{5}{6} \log \Delta+0.4343 \gamma \Delta+2.10,
$$

这里 $t$ 为波的频率.

利用中国各区 $\gamma 、 \log \left(A_{\max } / A_{L_{g}}\right)$ 和 $\log (H / Z)$ 实测值, 得到各区分别用振幅 $A_{L_{g}} 、 A_{L_{g}}$ 、 $A_{\mathrm{mxz}}$ 和 $A_{\mathrm{mxh}}$ 的分区 $m_{L_{g}}$ 公式. 其震级校准函数可统一成如下形岩:

$$
q_{\mathrm{rog} \text { ion }}(\Delta)=\frac{5}{6} \log \Delta+K \Delta+C,
$$

式中常数 $K$ 和 $C$ 值分别五个区四种振幅列于表 1 .

\begin{tabular}{|c|c|c|c|c|c|c|}
\hline & & \multirow{2}{*}{$\boldsymbol{K}$} & \multicolumn{4}{|c|}{$c$} \\
\hline & & & $L_{z^{*}}$ & $L_{\mathrm{z}} h$ & $m \times z$ & $m \times h$ \\
\hline 东部 & $q_{\mathrm{B}}$ & 0.00147 & 2.10 & 1.97 & 1.94 & 1.81 \\
\hline 西北 & $a_{N W}$ & 0.00091 & 2.10 & 2.00 & 1.98 & 1.88 \\
\hline 华南 & $q_{\mathrm{s}}$ & 0.00096 & 2.10 & 2.03 & 1.95 & 1.88 \\
\hline 西南 & $q_{9 \mathrm{gv}}$ & 0.00135 & 2.10 & 1.97 & 1.86 & 1.73 \\
\hline 东北 & $q_{\mathrm{NB}}$ & 0.0012 & & & 1.90 & 1.81 \\
\hline 全国 & 9 & 0.0012 & 2.10 & 1.99 & 1.93 & 1.82 \\
\hline
\end{tabular}

$$
\text { 表 } 1 \quad q_{\text {restoos }}(\Delta)=\frac{5}{6} \log \Delta+K \Delta+C
$$

取各区 $K$ 和 $C$ 的平均值作为全国统一的 $K$ 和 $C$, 列于表 1 的最后一行. 鉴于中国习惯使 用 $A_{m x b}$ 测定近震震级, 故定义中国统一 $m_{L_{g}}$ 为

式中

$$
m_{L_{g}}(\mathrm{~m} \times \mathrm{h})=\log A_{\mathrm{mxb}}+q(\Delta)+D_{\mathrm{h}},
$$

$$
q(\Delta)-\frac{5}{6} \log \Delta+0.0012 \Delta+1.82,
$$


$D_{\mathbf{z}}$ 为 $H$ 向震级台基校正值. 当必须利用 $A_{L_{g}} 、 A_{L_{g} h}$ 或 $A_{\operatorname{mxz}}$ 振幅时, 则需将上式中的学数项 分别改成 $2.10 、 1.99$ 或 1.93; 并对于 $Z$ 向振幅,需将 (4)式中的 $D_{\mathrm{b}}$ 改成 $D_{\mathrm{z}}$ ( $\mathrm{Z}$ 向台基校正值). ·不同 $A$ 测定的各 $m_{L_{g}}$ 值之差一般均小于 0.1 级.

(3)和(4)式适用于 $0.5^{\circ}$ 至 $10^{\circ}$ 震中距范围内, 对 DD-1、64 和 65 型等短周期笔绘地震 仪的测定. 对于光记录 BGK 地震仪, 其震级测定值则应加上- 0.21 级的仪器校正.

测定了 211 个中国区域台站的台基校正值 $D_{\mathrm{z}}$ 和 $D_{\mathrm{h}}$. 对于沉积岩、花岗岩和松散沉积台 基,其平均值分别为 $D_{\mathrm{z}}=-0.01,0.04$ 和 $-0.45, D_{\mathrm{h}}=-0.02,0.07$ 和 -0.65 .

使用统一 $m_{L_{g}}$ 代替各分区 $m_{L_{g}}$, 有利于全国统一测定. 由此引起的台网震级差, 以及约在 $500 \mathrm{~km}$ 以内的单台辰级差,一般均小于 0.1 级.

金安蜀和安艺 ${ }^{(n)}$ 利用尾波观测取得了中国地区 $1 \mathrm{~Hz} Q$ 值等值线图. 从该图与图 1 的比 较看出: 尾波 $Q$ 与 $L g$ 波 $Q$ 的区域分布大体吻合. 新疆地区主要分布 $Q-400$ 和 600 的等 值线, 其平均 $Q$ 值约与全国平均 $Q$ 值相近. 由此推断, 本文得到的中国统一 $m_{L_{\mathrm{e}}}$ 霞级公式 (4) 和(5)可以推广至新疆地区,即适用于除西藏以外的整个中国大陆地区.

中国统一 $m_{L_{g}}$ 标度与美国的 $m_{\mathrm{b} L_{\mathrm{o}}}$ 标度基本一致. 并且在约 2-6 级范围内, $m_{L_{\mathrm{e}}}$ 标度基 本上维持了中国现行使用的 $M_{\mathrm{L}}(\mathrm{CHN})$ 标度的历史震级水平. 中国统一 $m_{L}$ 标度的建立将 有利于推动中国各地区之间以及全球各大陆地区之间近震震级标度的统一.

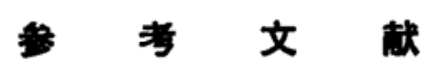

[1] Knopoff, L., Schwab, F. et al., Geophys. J.R. Astr. Soc., 33 (1973) 389-404.

[2] Bouchon, M., J. Geophys. Res., 87(1982), 1735-1741.

[3] 慕涣称,国际地震动态, 1988,10; 1-7.

[4] Nuttli, O.W., J. Geophys. Res., 78(1973), 876-885.

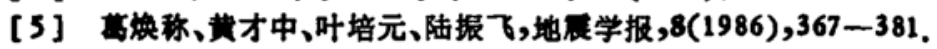

[6] Herrmann, R.B. and Kijko, A., Bull. Seism. Soc. Am., 73(1983), 1835-1850.

[7] Jin, A. and Aki, K., Bwll. Seism. Sec. Am., 78(1988), 141-789. 